plus beryllium source equivalent to about 400 millicuries radon plus beryllium during soventeen days. One hour forty minutes after the irradiation had been interrupted, the glass tube with sodium pyrouranate was connected to a water pump and a stream of pure air (radon-free) was passed through it during 50 minutes to remove any radium emanation and the gaseous products of fission, which might have been accumulated in the uranium. Then a glass tube with pure silica-gel cooled to the temperature $-110^{\circ} \mathrm{C}$. was placed between the tube with pyrouranate and the water pump and a stream of pure air was passed through the system for four hours. The silica.gel was then treated by hot dilute $(1: 5)$ hydrochloric acid to which some barium, strontium and lanthanum salts were added. The solution was filtered under suction and a complete chemical separation of lanthanum, barium and strontium was performed. The lanthanum, barium and strontium precipitates were found to be radioactive and showed the following half-lifo poriods : La $+\mathrm{K}, T \sim 30 \mathrm{~m} ., T \sim 9 \mathrm{~h} .30 \mathrm{~m}$., and $T \sim 45 \mathrm{~h}$.; Sr, $T \sim 20 \mathrm{~m} ., T \sim 7 \mathrm{~h} .30 \mathrm{~m}$. and one isotope of much longer period; and $\mathrm{Ba}, T \sim 10 \mathrm{~h}$. and $T \sim 50 \mathrm{~h}$.

To find out whether the gaseous radio-elements are in the middle or at the beginning of the transmutation chain, we have separated the fission products of uranium from uranium oxide irradiated for 36 hours by slow neutrons from a cyclotron. The intensity of the neutron beam was equivalent to about 30 curies of radon plus beryllium. We were ablo to collect, from the walls of the vessel in which that preparation was contained, the produets of transformation of the gaseous radio-elements.

These two experiments show definitely that thero exist two new fission processes of uranium under bombardment by slow noutrons, with radioactive isotopes of krypton and xenon as intermediary products of the fission, coming in the middle of the transmutation chain ${ }^{2}$.

Further experiments will be mado in order to estimate the half-life period of these new radioactive isotopes of krypton and xenon and to search for the beginning of these transmutation chains.

IV. G. Chlorin.

II. A. Passwik-Ciropin.

N. F. Wolkov.

Radium Institute of the

Academy of Science of the U.S.S.R., Leningrad.

July 21.

Wolkov, X. F., C.R. Acad. Sci, URSS. (in the press).

"Hahn, O., und Strassmann, F., Naturt iss., 27, 89 (1939); Aten, jun., A. II., Bakker, C., und Xesn, F. A., Nature, 143, 510 (1939).

\section{Comparison of Resistances of Four Terminal Resistors}

THE only precise method given in the standard text-books for the comparison of the resistances of four terminal resistors is the Kelvin double bridge, and it appears to be the only one used for this purpose. The method described below is at least as precise and should, in my opinion, bo as well known.

Thə circuit is shown in the accompanying figure, in which $R$ and $X$ are the standard and unknown resistances respectively ; $a$ is a fixed resistance, conveniently one of the ratio arms of a standard bridge and $b$ is the variable arm of the bridge.
With the switch on contact 1 a balance is obtained and $\mathrm{a}$ second balance with the switch on contact 2 . If the values of $b$ for the balances are $b$ and $b^{\prime}$

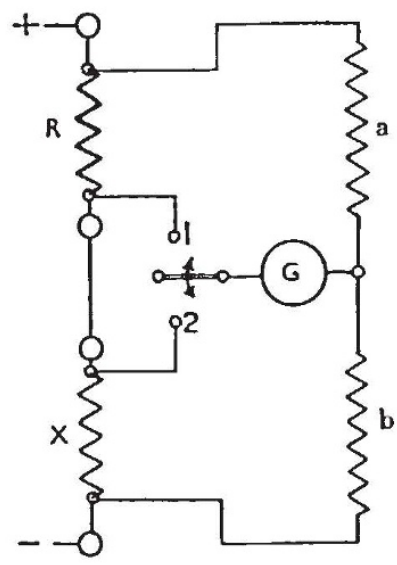

respectively and $r$ is the resistance between the inner potential terminals, we may write :

$$
R . b=a(X+r) \text { and } b^{\prime}(R+r)=X . a .
$$

Hence

$$
\frac{R}{X}=\frac{a\left(a+b^{\prime}\right)}{b^{\prime}(b+a)}
$$

This method has the following advantages over the doublo bridgo, (1) less apparatus is required, (2) the effective sensitivity of the galvanometer is greater, and (3) no current passes, at balanco, through two of the four potential terminals.

College of Technology,

Arvon Glynne.

Manchester.

August 4.

Inactivation of Diethylstilbcestrol in the Organism

Is provious reports ${ }^{1}$ it has been demonstrated that the sex hormones (œstrone, progesterone) are rapidly rendered inactive in tho organism. If a rat is injected with 1,000 I.U. œstrone no more than 1-2 per cent of this substance can be recovered from the organism by organic solvents after a period of forty-eight hours. In contradistinction to this, the hormono esters (œstronebenzoate, œstradiolbenzoate) are very largely recovered. These findings have been corroborated by Laqueur ${ }^{2}$, who was able to demonstrate at the same timo that the hormone esters remained deposited at the site of injection. They do not undergo slow decomposition in the blood, but are slowly absorbed from the site of injection.

Wo proceeded to investigate the behaviour of $4: 4^{\prime}$-dihydroxy $\alpha$ - $\beta$-diethylstilbene (diethylstilbostrol) which was described by Dodds, Golberg, Lawson and Robinson in $1938^{3}$. The authors, in a most instructive descriptive sketch, demonstrated the resemblance between theso ostrogenic substances and ostradiol. Hence we compared the inactivation of stilboestrol with that of ostradiolbenzoate and some other œstrogens.

Infantile rats were injected with 1,000 r.u. of cstrogenic substance dissolved in 0.1 c.c. of oil. After forty-eight hours tho animals were killed and an attempt was made to recover the œstrogenic hormone from the whole body of the animal by 